\title{
Effectiveness of circular external fixator in periprosthetic fractures around the knee
}

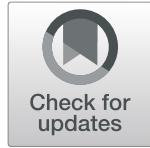

Koji Nozaka* (D, Naohisa Miyakoshi, Michio Hongo, Yuji Kasukawa, Hidetomo Saito, Hiroaki Kijima, Hiroyuki Tsuchie, Motoki Mita and Yoichi Shimada

\begin{abstract}
Background: The incidence of periprosthetic fractures after total joint arthroplasty (TJA) is rising due to an increasing number of TJAs performed annually and the growing elderly population. In many elderly patients with periprosthetic fractures, the bone strength is lowered due to the deterioration of bone quality and a decrease in bone quantity; rigid fixation of the fracture is difficult. It is a challenging operation for orthopedic surgeons. The usefulness of circular external fixation for periprosthetic fractures has been reported in several case studies. The aim of this study was to investigate the rate of union and complications associated with circular external fixation in periprosthetic fractures around the knee.
\end{abstract}

Methods: We included 19 patients with periprosthetic femur and tibial fractures who underwent osteosynthesis using a circular external fixator and had at least 2 years of follow-up. All patients had comorbidities and high risks associated with anesthesia. Tourniquets were not used in any of the patients. There were no cases in which the skin incision was placed, and the closed reduction technique was used in all cases.

Results: A 100\% union rate was achieved with no serious complications. All fractures healed after a mean time of $14.3 \pm 5.2$ weeks (range, 8-38 weeks). The walking ability was the same level as before the injury in 13 cases.

Discussion: There are many comorbidities associated with periprosthetic fractures in elderly patients. Double-plate or revision surgery were largely invasive and had high risks associated with anesthesia. Circular external fixation is a feasible and effective treatment option because it provides stable fixation, prompt postoperative mobilization, and has no major complications, especially in elderly patients who are treated for periprosthetic fractures.

Conclusion: Circular external fixation is a safe and reliable method for periprosthetic fractures around the knee in elderly patients.

Level of evidence: Level IV, retrospective case series.

Keywords: Circular external fixation, Periprosthetic fractures around the knee, Union rate, Walking level, Closed reduction technique

\footnotetext{
* Correspondence: kk-nozaka@mue.biglobe.ne.jp

Department of Orthopedic Surgery, Akita University Graduate School of

Medicine, 1-1-1 Hondo, Akita 010-8543, Japan
}

(C) The Author(s). 2020 Open Access This article is licensed under a Creative Commons Attribution 4.0 International License, which permits use, sharing, adaptation, distribution and reproduction in any medium or format, as long as you give appropriate credit to the original author(s) and the source, provide a link to the Creative Commons licence, and indicate if changes were made. The images or other third party material in this article are included in the article's Creative Commons licence, unless indicated otherwise in a credit line to the material. If material is not included in the article's Creative Commons licence and your intended use is not permitted by statutory regulation or exceeds the permitted use, you will need to obtain permission directly from the copyright holder. To view a copy of this licence, visit http://creativecommons.org/licenses/by/4.0/ The Creative Commons Public Domain Dedication waiver (http://creativecommons.org/publicdomain/zero/1.0/) applies to the data made available in this article, unless otherwise stated in a credit line to the data. 


\section{Background}

The incidence of periprosthetic fractures after total joint arthroplasty (TJA) is rising due to an increasing number of TJAs performed annually and the growing elderly population. With an increase in the number of elderly patients with osteoporosis, artificial femoral head replacement (FHR) is also emerging as a simple procedure for femoral neck fractures $[1,2]$. Furthermore, because total hip arthroplasty (THA) and total knee arthroplasty (TKA) generally result in prolonged use of the artificial joint, the incidence of periprosthetic fracture also increases in elderly patients after TJA and FHR. Periprosthetic fractures often result from minor trauma [1], which may be due to inappropriate placement of the components during surgical procedures (i.e. femoral notch), sex-related differences, osteoporosis, rheumatoid arthritis, neurological diseases, steroid use, or stress shielding [3, 4]. In many elderly patients with periprosthetic fractures, the bone strength is lowered due to the deterioration of bone quality and a decrease in bone quantity; rigid fixation of the fracture is also difficult [5]. The union rate of periprosthetic fracture ranges from 60 to $70 \%$, according to previous literature $[6,7]$, and it is a challenging operation for orthopedic surgeons [4]. Because there are many elderly patients with periprosthetic fractures, it is important to establish minimally invasive surgical techniques for treatment and promote early rehabilitation. In some cases, conservative treatment is chosen because there are high risks associated with anesthesia or surgery is otherwise difficult to perform. However, in such cases, a long-term non-weight bearing period is necessary for effective healing. Furthermore, the union rate of conservative treatment for periprosthetic fractures around the knee is not high $[8,9]$. Few patients are capable of restoring their walking ability, even after the long-term non-weight bearing period, which is required for conservative treatment. Circular external fixation is advantageous because it ensures rigid

\begin{tabular}{|c|c|c|c|c|c|c|c|}
\hline Case no. & $\begin{array}{l}\text { Sex/age } \\
\text { (years) }\end{array}$ & $\begin{array}{l}\text { Follow-up } \\
\text { (months) }\end{array}$ & Comorbidities & $\begin{array}{l}\text { Vancouver } \\
\text { classification }\end{array}$ & $\begin{array}{l}\text { Lewis-Rorabeck } \\
\text { classification }\end{array}$ & $\begin{array}{l}\text { Felix classification } \\
\text { type }\end{array}$ & $\begin{array}{l}\text { Time to union } \\
\text { (weeks) }\end{array}$ \\
\hline 1 & $\mathrm{~F} / 87$ & 54 (died) & Rheumatoid arthritis, Untreated osteoporosis & C & & & 15 \\
\hline 2 & $\mathrm{M} / 80$ & 72 & $\begin{array}{l}\text { Chronic heart failure, Chronic renal failure, } \\
\text { Untreated osteoporosis }\end{array}$ & C & & & 11 \\
\hline 3 & $F / 69$ & 89 & Hypertension, Untreated osteoporosis & C & & & 12 \\
\hline 4 & $M / 69$ & 73 & Hypertension, Diabetes mellitus & C & & & 20 \\
\hline 5 & $\mathrm{~F} / 81$ & 50 & Hypertension, Diabetes mellitus, osteoporosis & & & & 10 \\
\hline 6 & $\mathrm{~F} / 87$ & 88 & $\begin{array}{l}\text { Hypertension, Diabetes mellitus, Untreated } \\
\text { osteoporosis }\end{array}$ & & $\|$ & & 12 \\
\hline 7 & $\mathrm{~F} / 83$ & 85 & Hypertension, Untreated osteoporosis & & $\|$ & & 12 \\
\hline 8 & $\mathrm{~F} / 80$ & 49 & Diabetes mellitus, Untreated osteoporosis & & $\|$ & & 11 \\
\hline 9 & $\mathrm{~F} / 88$ & 52 & Hypertension, Untreated osteoporosis & & $\|$ & & 11 \\
\hline 10 & $\mathrm{~F} / 81$ & 69 & $\begin{array}{l}\text { Hypertension, Diabetes mellitus, Chronic heart } \\
\text { failure, Untreated osteoporosis }\end{array}$ & & $\|$ & & 8 \\
\hline 11 & $\mathrm{~F} / 87$ & 51 & $\begin{array}{l}\text { Hypertension, Diabetes mellitus, Chronic heart } \\
\text { failure, Untreated osteoporosis }\end{array}$ & & $\|$ & & 12 \\
\hline 12 & $\mathrm{~F} / 84$ & 16 & $\begin{array}{l}\text { Hypertension, Chronic heart failure, Untreated } \\
\text { osteoporosis }\end{array}$ & & $\|$ & & 11 \\
\hline 13 & $F / 68$ & 89 & $\begin{array}{l}\text { Hypertension, Diabetes mellitus, Untreated } \\
\text { osteoporosis }\end{array}$ & & ॥ & & 15 \\
\hline 14 & $\mathrm{~F} / 79$ & 75 & Untreated osteoporosis & & $\|$ & & 10 \\
\hline 15 & $M / 64$ & 57 & Diabetes mellitus & & $\|$ & & 27 \\
\hline 16 & $\mathrm{M} / 70$ & 68 & Diabetes mellitus & & $\|$ & & 11 \\
\hline 17 & $\mathrm{~F} / 64$ & 24 & $\begin{array}{l}\text { Rheumatoid arthritis, Hypertension, } \\
\text { Osteoporosis }\end{array}$ & & $\|$ & & 12 \\
\hline 18 & $\mathrm{~F} / 84$ & 70 & $\begin{array}{l}\text { Severe anemia, Severe obesity, Hypertension, } \\
\text { Diabetes mellitus, Osteoporosis }\end{array}$ & & $\|$ & & 38 \\
\hline 19 & $\mathrm{~F} / 84$ & 19 (died) & $\begin{array}{l}\text { Rheumatoid arthritis, Hypertension, Diabetes } \\
\text { mellitus, Untreated osteoporosis }\end{array}$ & & & $\| \mathrm{A}$ & 10 \\
\hline Mean & 79.2 & 62.8 & & & & & 14.1 \\
\hline
\end{tabular}

F, female; $M$, male 
fixation through the insertion of several thin $1.8-\mathrm{mm}$ wires. Furthermore, immediate full weight-bearing after surgery is possible because of rigid fixation.

In addition, by using ligamentotaxis, reduction is possible from the outside of the body, even in large displacement fractures. Osteosynthesis can be completed using a minimally invasive surgical technique and does not require exfoliation or incision of the skin and/or muscle around the fracture site. The usefulness of circular external fixation for periprosthetic fractures has been reported in several case studies [10-13]. In addition, the Ilizarov technique is an effective treatment method for complex limb injuries that is especially applicable in developing or poor countries, and furthermore, in secondary care public hospitals with limited resources [14].

The aim of this study was to investigate the rate of union and complications associated with circular external fixation among elderly patients with periprosthetic fractures.

\section{Methods}

We included 19 patients (4 males and 15 females; mean age: 79.2 years; age range: $60-88$ years) with periprosthetic femur and tibial fractures who underwent osteosynthesis using a circular external fixator and had $\geq 2$ years of follow-up. Eleven patients were classified with Rorabeck type II fractures [15], 6 were classified with Vancouver type $C$ fractures, and 1 had a periprosthetic tibial fracture classified according to previously described criteria [16]. One patient experienced periprosthetic fracture between THA and TKA. All periprosthetic fractures were caused by low-energy trauma and the left side was affected in 10 patients. All patients had comorbidities (Table 1). Three patients $(15.8 \%)$ were receiving treatment for osteoporosis at the time of admission. All patients had low activity levels; for example, four patients walked with rollator, eight patients walked with the assistance of a $\mathrm{T}$-cane, and seven patients were able to walk with no assistance. In all the patients, the anatomical axis of the lower limb was examined before the injury and after surgery. Postoperative bone mineral density (BMD) was measured in 14 patients, and the average BMD of the femur was $0.367 \pm 0.028 \mathrm{~g} / \mathrm{cm}^{2}$. Surgery was requested due to the difficulty associated with inserting an intramedullary nail. Moreover, doubleplate or revision surgery were largely invasive and had high risks associated with anesthesia. Therefore, a circular external fixator was used in all patients. Tourniquets were not used in any patients. Skin incisions were not used in any cases, and all cases were reduced using the closed reduction technique. All patients were allowed to walk with full weight-bearing immediately after surgery (Fig. 1). The knee jointspanning external fixator was used (Fig. 2), the tibial ring (or femur ring; case 19) was removed 2 weeks after surgery, and range of motion (ROM) exercises were started. All patients were examined for pin-tract infection by using erythrocyte sedimentation rate (ESR) and C-reactive protein (CRP) levels as common inflammatory markers. ESR and CRP levels were measured every 2 weeks after surgery [17].

\section{Surgical technique for periprosthetic femur fracture}

First, two straight wires were inserted into the proximalto-mid femur and attached to the proximal full ring. Then, two straight wires were inserted into the proximal

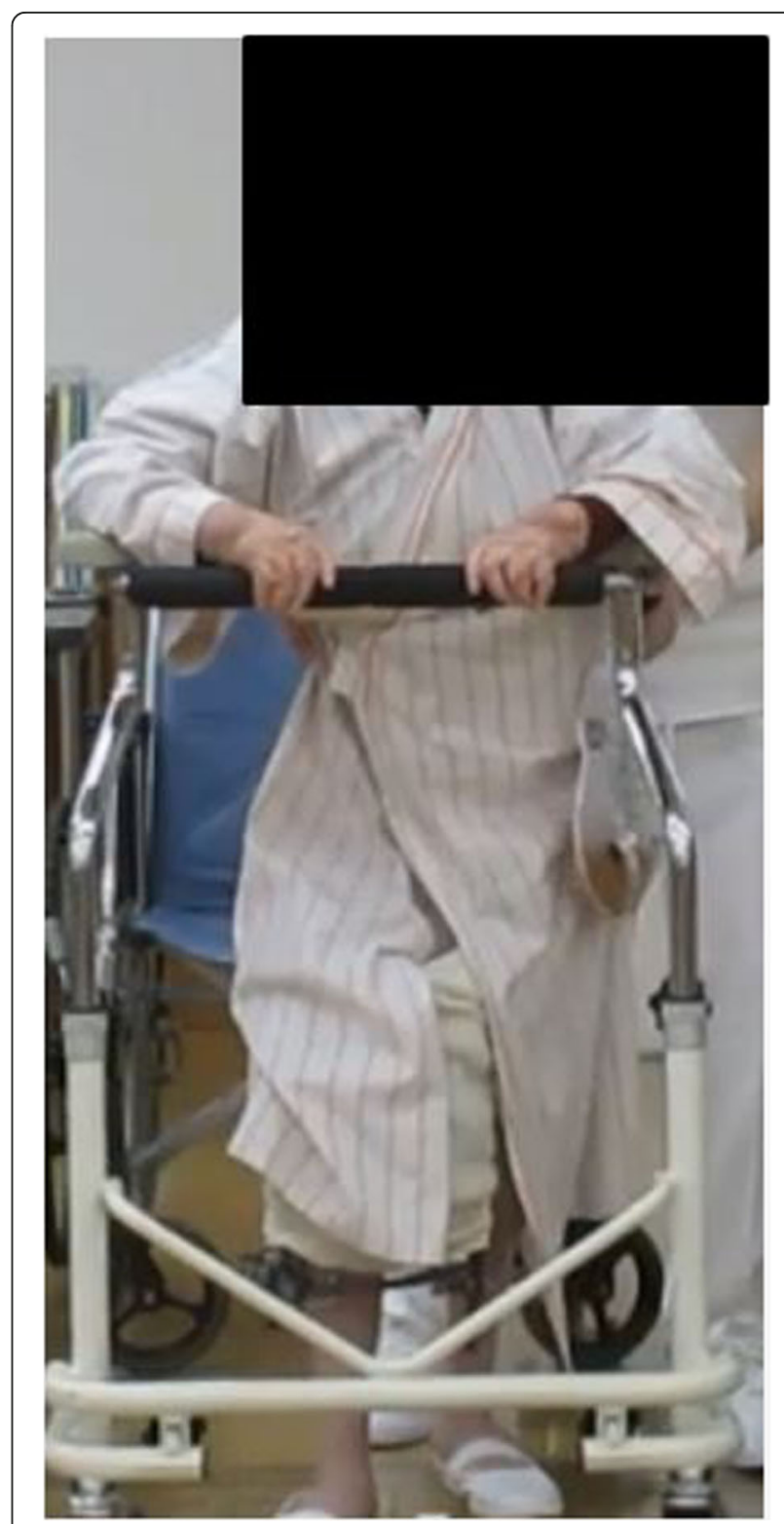

Fig. 1 Full weight-bearing walking immediately after surgery 


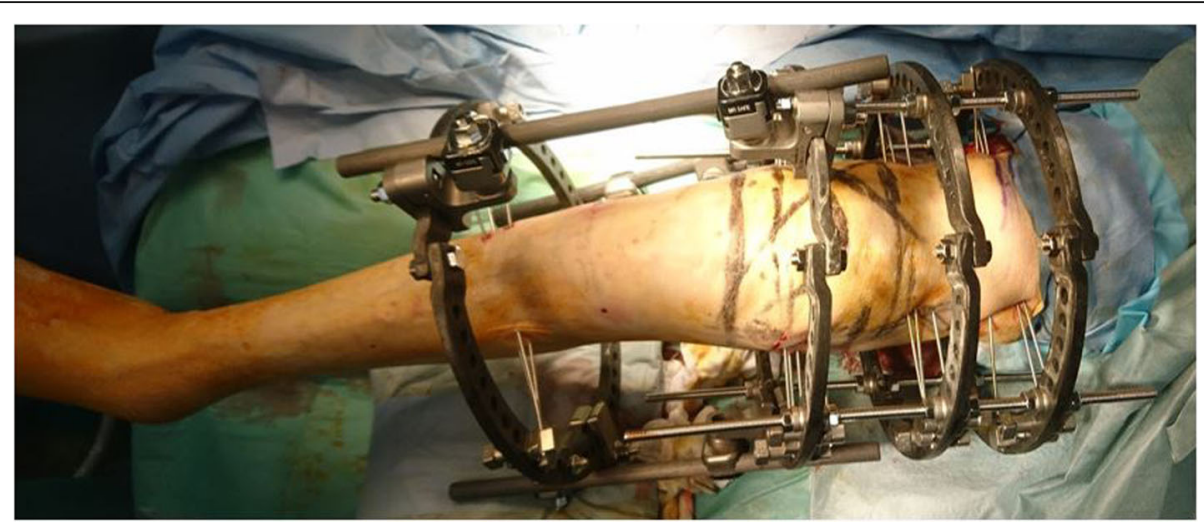

Fig. 2 The knee joint-spanning circular external fixator was used, the tibial ring was removed 2 weeks after surgery, and range of motion (ROM) exercises were started

tibia and attached to the ring. The middle 2 full rings were left free near the proximal ring so that they did not interfere when checking the reduction of the fracture area. An assistant held the proximal ring while the surgeon moved the distal tibia ring, which was anchored to the proximal tibia during distraction, flexion, extension, valgus, and varus. This maneuver was gently and carefully repeated over time. By relieving the "jamming" of the fracture area by longitudinal traction with a large force using the tibial ring, almost all dislocations (shortening, rotational, angular, axial) were accurately reduced by closed manipulation. A 2.4-mm Kirschner wire (Kwire) was inserted and fixed to the cross from the inside and outside of the distal fragment. The thin K-wires were inserted in the thick parts of the cortical bone as accurately as possible to prevent cutting of the osteoporotic bone [18]. In some cases, we performed the Kapandji K-wiring technique. We achieved closed reduction in all cases [18]. In addition, the surgeon used the olive wire technique to further reduce the dislocation. The middle 2 rings were anchored using straight wires. Finally, the parts of the rods that protruded distally were cut so that they did not interfere when checking the reduction.

\section{Results (Table 1, Figs. 3, 4, 5)}

A $100 \%$ union rate was achieved with no serious complications. All fractures healed after a mean time of $14.3 \pm$ 5.2 weeks (range, $8-38$ weeks). One patient had delayed union at 38 weeks. The mean follow-up period was $62.1 \pm 12.2$ months (range, 13-89 months). Three patients died from heart failure. The mean ROM after follow-up was $110^{\circ}$. Most of the patients felt that their knee flexion was restricted after surgery, compared to before the injury. The walking ability was the same level as before the injury in 13 patients, and 6 patients experienced a lowered walking ability after the surgery. None of the patients in this study showed a change in the anatomical axis of the lower limb after surgery as compared with before the injury. There were fourteen superficial pin-tract infections, which were treated with empirical oral antibiotics and daily pin-tract dressings. Nerve palsy, deep infection, deep venous thrombosis, or pulmonary embolism did not occur in any patients.

\section{Discussion}

The incidence of post-TKA supracondylar femoral fracture ranged from 0.3 to $2.5 \%$ in patients who had undergone TKA [19], while the incidence of post-THA peristem fracture ranged from 1 to $7.8 \%$ in patients who had undergone THA [20]. While periprosthetic fracture of the proximal tibia following TKA is rare, it may create a challenging clinical scenario. Although this fracture rarely occurs, periprosthetic fractures around the knee are usually difficult to treat. At present, the most commonly used materials for osteosynthesis are also used for internal fixation of fractures [21]. Surgical treatment is required for periprosthetic fractures with displacement, and a locking plate or retrograde intramedullary nail is often chosen. Using a retrograde intramedullary nail without exfoliation around the fracture site is advantageous for bone union because it allows preservation of the periosteum and peripheral soft tissue. However, the nail cannot be used in patients with severe knee contracture, patients with ipsilateral THA or FHR, or patients without intercondylar space due to TKAs (stem implants or closed box-type femoral components). The distal fragment must be large enough to allow the insertion of many screws so that adequate fixation can be achieved. When a locking plate is chosen for the fragile bone in periprosthetic fractures around the knee, rigid fixation is possible because several screws can be inserted in the distal bone fragment. Rollo et al. reported that plating and bone grafting may ensure better mechanical and biological support for the healing of periprosthetic fracture of the knee than simple plating [22]. In cases of 


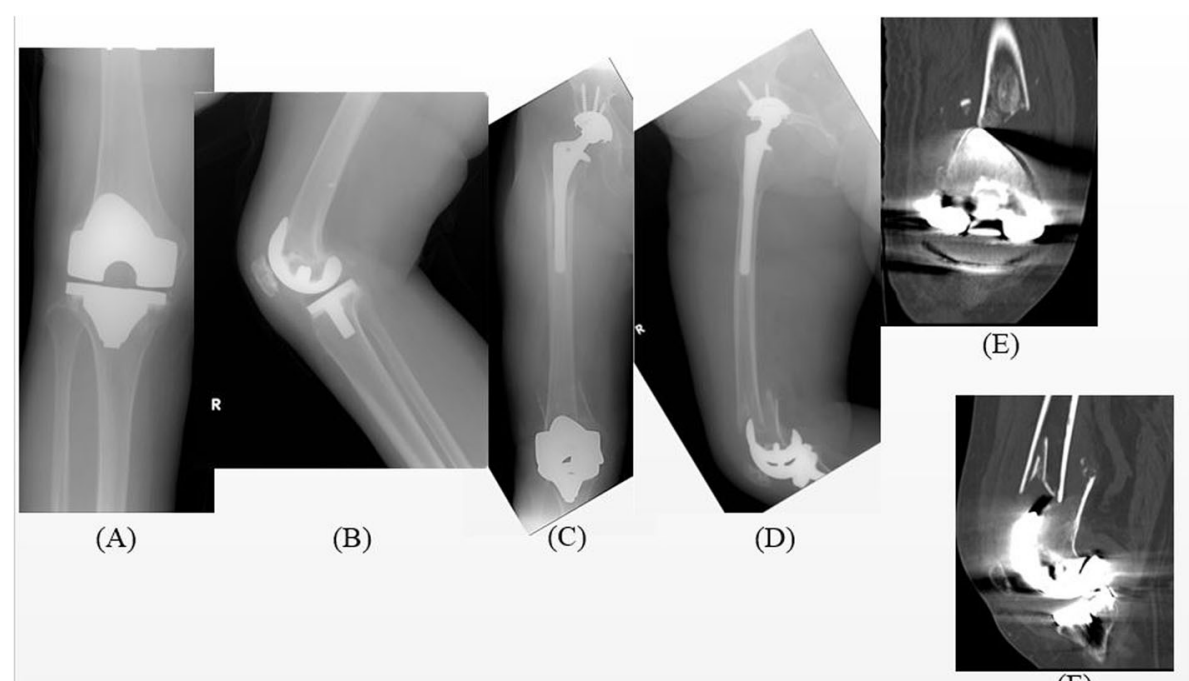

(F)

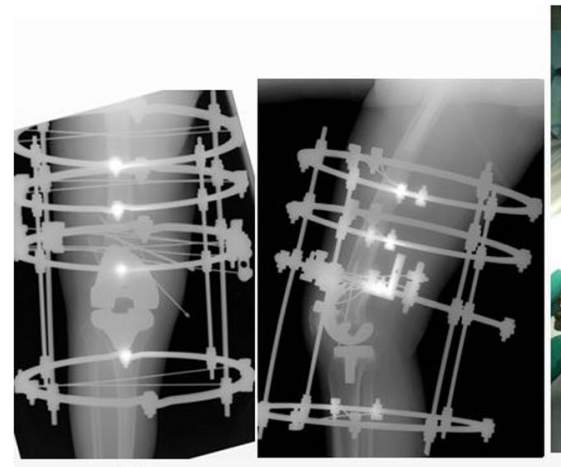

(G)

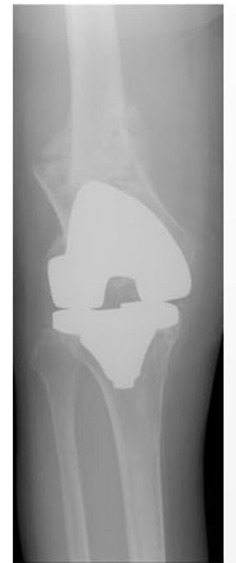

(K)
(H)

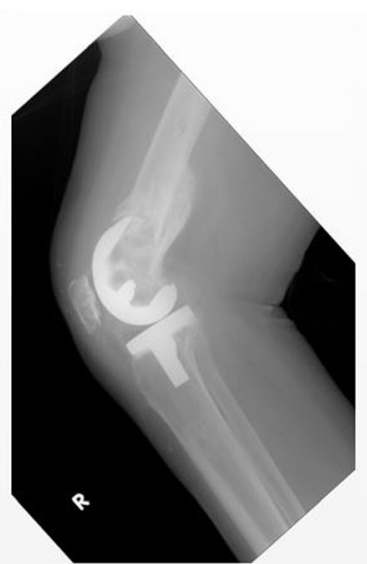

(L)

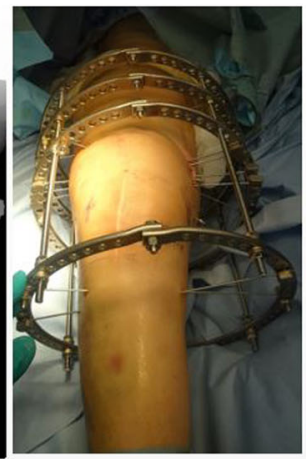

(I)

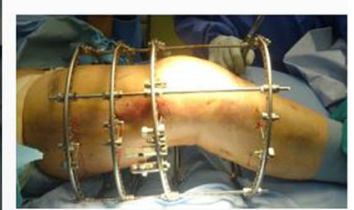

$(\mathrm{J})$

Fig. 3 Periprosthetic distal femur fracture in case number 5 treated with a circular external fixator. (A, B) The joint before injury. (C) Preoperative antero-posterior $X$-ray after the injury. (D) Preoperative lateral angle X-ray. (E) Preoperative coronal CT scan. (F) Preoperative sagittal CT scan. (G, H) Immediate postoperative X-ray. $(\mathrm{I}, \mathrm{J})$ Immediate postoperative clinical photograph. $(\mathrm{K}, \mathrm{L}) \mathrm{X}$-ray after removal of the circular external fixator and weight-bearing (10 weeks after the surgery). $(\mathrm{M}, \mathrm{N})$ Three years after the surgery. $\mathrm{CT}$, computed tomography

severe osteoporosis and comminuted fracture of the medial metaphysis, a double plate may be preferable. Considering the reduced bone union ability in the elderly, the minimally invasive plate osteosynthesis (MIPO) method, in which the soft tissue is largely exfoliated and the blood flow is not decreased, is expected to promote bone union. However, the MIPO method is limited to cases in which the dislocation of fracture site is very 


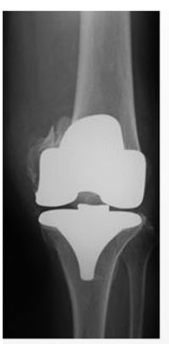

(A)

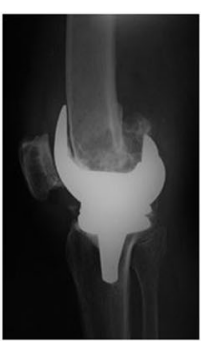

(B)

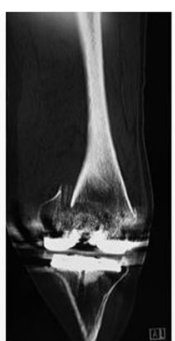

(C)

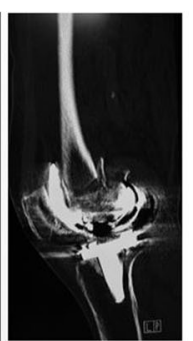

(D)

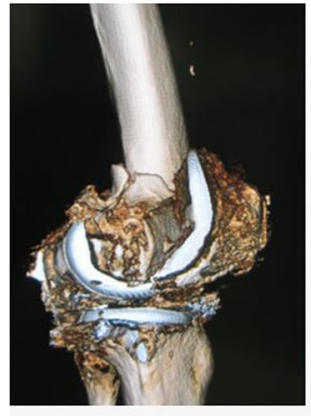

(E)

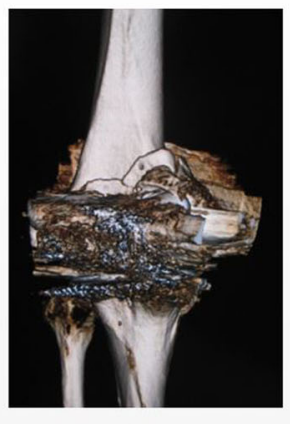

(F)

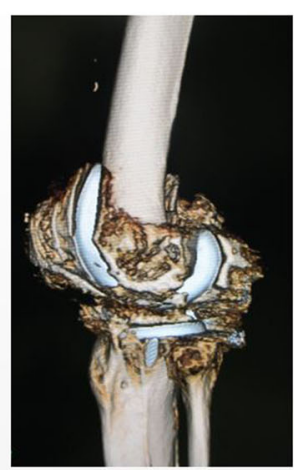

(G)

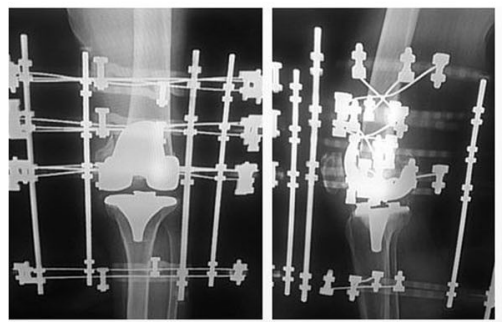

(H)

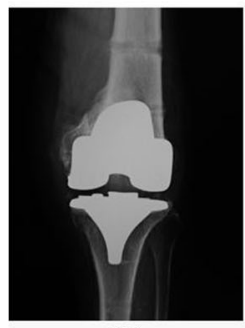

(L)

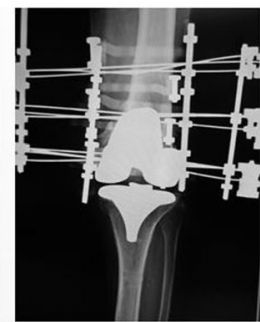

(J)

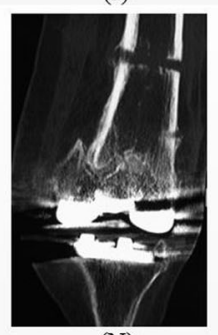

(N)

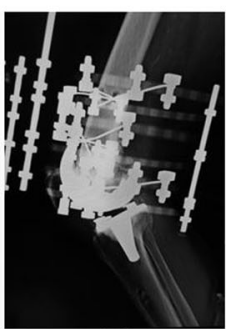

(K)

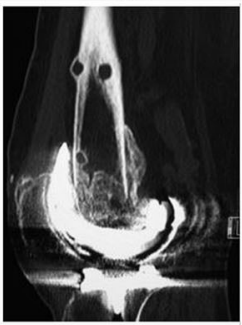

(O)

Fig. 4 Periprosthetic distal femur fracture in case number 11 treated with a circular external fixator. (A) Preoperative antero-posterior X-ray. (B) Preoperative lateral angle X-ray. (C) Preoperative coronal CT scan. (D) Preoperative sagittal CT scan. (E) Preoperative medial-lateral angle 3D CT. (F) Preoperative posterior-anterior 3D CT. (G) Preoperative lateral-medial angle 3D CT. (H, I) Immediate postoperative X-ray. (J) Antero-posterior X-ray 2 weeks after removal of the tibial ring. (K) Lateral angle X-ray 2 weeks after removal of the tibial ring. (L,M) X-ray after circular external fixator removal and weight-bearing, postoperative 12 weeks. $(\mathrm{N}, \mathrm{O}) \mathrm{CT}$ after circular external fixator removal and weight-bearing, postoperative 12 weeks. $\mathrm{CT}$, computed tomography; 3D, three-dimensional

small [1]. It is necessary to adequately expand or reduce the fracture site for cases in which the amount of preoperative fracture dislocation (shortening, rotational, angular, axial) is large. In addition, when the double-plate is used to increase the fixation, the surgery becomes more invasive. Matlovich et al. compared 38 patients who received a locking plate with 19 patients who received an intramedullary nail and reported no significant differences regarding the fusion time or postoperative outcomes [23]. Both retrograde intramedullary nailing and plate fixation require non-weight bearing for approximately 4 to 6 weeks after surgery. Most cases of periprosthetic fracture in elderly patients are associated with poor motor function and difficulty in walking with crutches; therefore, it is difficult to recover the walking ability of patients with disuse syndrome, which is 


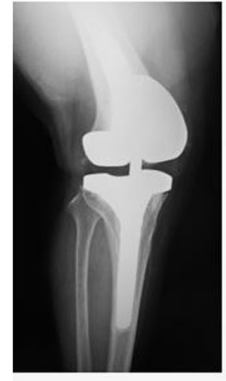

(A)

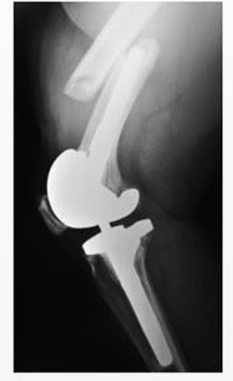

(B)

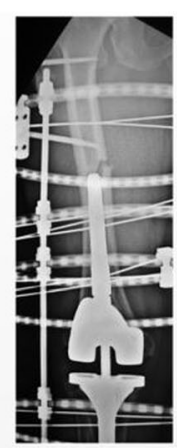

(C)

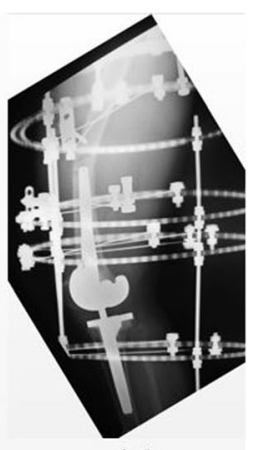

(D)

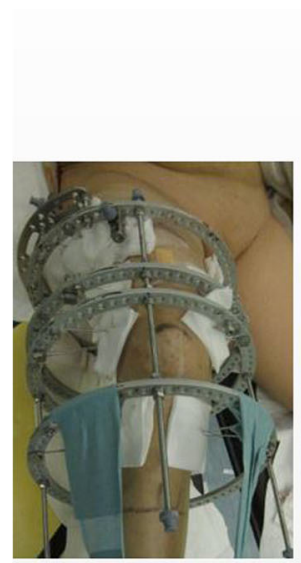

(E)

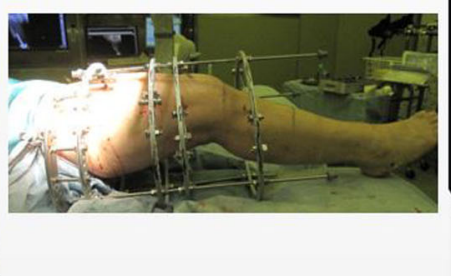

(F)

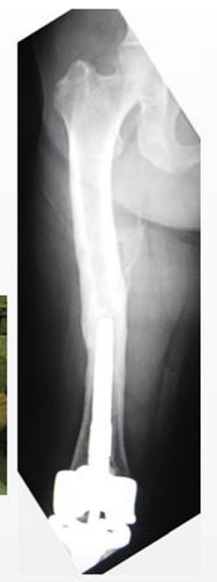

(G)

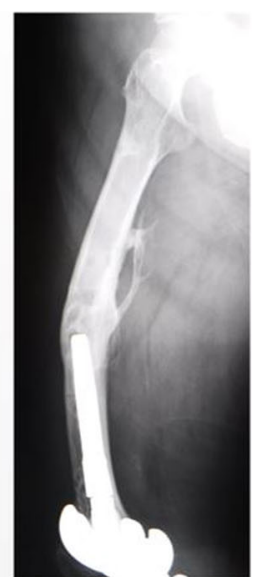

(H)

Fig. 5 Periprosthetic distal femur fracture in case number 18 treated with a circular external fixator. (A) Preoperative antero-posterior $X$-ray. (B) Preoperative lateral angle X-ray. (C, D) Immediate postoperative X-ray. (E, F) Immediate postoperative clinical photograph. $(G, H)$ Postoperative 5 years

commonly caused by non-weight bearing for a long time after treatment.

There are many comorbidities associated with periprosthetic fractures in elderly patients; there were only a few cases in this study in which the patient did not have a low activity level or difficulty walking. In patients with high preoperative risks, conservative treatment is chosen. It is very difficult for elderly patients to walk again after long-term non-weight bearing. In addition, many patients who undergo internal fixation for periprosthetic fracture can touch their toes and withstand $1 / 3$ full weight-bearing 2-4 weeks postoperatively, and full weight-bearing by 4-8 weeks postoperatively. On the other hand, most patients receiving circular external fixation in this study were able to withstand partial weight-bearing 1 day postoperatively and full weightbearing 2 weeks postoperatively.

Some reports have indicated that a major advantage of circular external fixation is the ability to achieve rigid fixation for osteoporotic bones, which can be obtained through the insertion of multiple thin, straight wires [10]. Beris et al. reported that circular external fixation is a feasible and effective treatment option because it provides stable fixation, prompt postoperative mobilization, and has no major complications, especially in elderly patients who are treated for periprosthetic fractures [10]. Furthermore, gentle closed reduction and fixation are beneficial for effective bone union, in terms of biological characteristics and vascularization of the fracture area [24]. In addition, none of the patients showed any change in the anatomical axis of the lower limb after surgery in this study. Falzarano et al. reported no significant difference in the anatomical axis of the nonarticular tibial fracture between the hybrid external, plate and screw, and intramedullary nailing fixation groups [25].

This approach carries a risk of pin-tract infections. When treating periprosthetic fractures around the knee with a circular external fixator, meticulous pin care and immediate treatment with antibiotics are necessary at any sign of infection [18, 26-32]. Falzarano et al. reported that ESR and CRP levels proved to have greater diagnostic accuracy in predicting late chronic and early postoperative infections in THA. These markers are valuable support 
for the surgeon in monitoring early postoperative superficial pin-tract infection of the circular external fixator in periprosthetic fractures around the knee. We conducted postoperative evaluation for the prevention of pin-tract infection, using ESR and CRP levels as common inflammatory markers [17].

This study has some limitations that should be addressed. First, patients may find the use of a circular external fixator uncomfortable. However, immediate full weight-bearing after surgery is possible because of rigid fixation. Secondly, most of the patients felt that their knee flexion was more restricted after the surgery than before the injury. Additional studies with a larger number of elderly patients with periprosthetic fractures around the knee are needed to confirm the use of a circular external fixator as a feasible and effective treatment option.

\section{Conclusions}

At the hands of an expert, circular external fixation is a minimally invasive surgical technique that can be performed rapidly without major complications. Our study indicates that circular external fixation is a safe and reliable method for treating periprosthetic fractures around the knee in elderly patients.

\section{Abbreviations}

TJA: Total joint arthroplasty; FHR: Femoral head replacement; THA: Total hip arthroplasty; TKA: Total knee arthroplasty; BMD: Bone mineral density; ROM: Range of motion; ESR: Erythrocyte sedimentation rate; CRP: C-reactive protein; MIPO: Minimally invasive plate osteosynthesis

\section{Acknowledgements}

Not applicable.

\section{Authors' contributions}

KN performed the surgery. MN helped with surgery and helped to draft the manuscript. MH, YK, HS, HK, HT and MM assisted with the surgery. YS helped draft the manuscript. All authors read and approved the final manuscript.

\section{Funding}

The author(s) received no financial support for the research, authorship, and/ or publication of this article.

\section{Availability of data and materials}

The datasets used and/or analyzed during the current study are available from the corresponding author on reasonable request.

\section{Ethics approval and consent to participate}

All participants received prior information about the study before providing their written informed consent in accordance with the declaration of Helsinki. The study was approved by the ethical committee of Akita University Hospital (registration number 1970).

\section{Consent for publication}

Written informed consent was obtained from the patients for publication of this research and any accompanying images. A copy of the written consent is available for review by the Editor of this journal.

\section{Competing interests}

All authors declare that they have no competing interests.
Received: 26 January 2020 Accepted: 18 May 2020

Published online: 21 May 2020

\section{References}

1. Lenz M, Lehmann W, Wähnert D. Periprosthetic fracture fixation in osteoporotic bone. Injury. 2016:47(Suppl 2):S44-50. https://doi.org/10.1016/ S0020-1383(16)47008-7.

2. Ebraheim NA, Kelley LH, Liu X, Thomas IS, Steiner RB, Liu J. Periprosthetic distal femur fracture after Total knee Arthroplasty: a systematic review. Orthop Surg. 2015;7(4):297-305. https://doi.org/10.1111/os.12199 Review.

3. Minarro JC, Urbano-Luque MT, López-Jordán A, López-Pulido MJ, GonzálezFernández Á, Delgado-Martínez AD. Is the fracture pattern in periprosthetic fractures around the knee related with the anterior femoral notch? J Clin Orthop Trauma. 2018;9(4):289-91. https://doi.org/10.1016/j.jcot.2017.10.001 Epub 2017 Oct 5.

4. Park KC, Lim SJ, Song YS, Hwang KT. Factors affecting peri-implant fracture following locking plate for osteoporotic distal femur fractures. Orthop Traumatol Surg Res. 2017;103(8):1201-4. https://doi.org/10.1016/j.otsr.2017. 08.008 Epub 2017 Sep 19.

5. Nagoya S, Tateda K, Okazaki S, Kosukegawa I, Shimizu J, Yamashita T. Restoration of proximal periprosthetic bone loss by denosumab in cementless total hip arthroplasty. Eur J Orthop Surg Traumatol. 2018;28(8): 1601-7. https://doi.org/10.1007/s00590-018-2223-x Epub 2018 May 17.

6. Large TM, Kellam JF, Bosse MJ, Sims SH, Althausen P, Masonis JL. Locked plating of supracondylar periprosthetic femur fractures. J Arthroplast. 2008;23(6 Suppl 1):115-20. https://doi.org/10.1016/j.arth.2008.04.021 Epub 2008 Jul 9.

7. Gondalia V, Choi DH, Lee SC, Nam CH, Hwang BH, Ahn HS, Ong AC, Park HY, Jung KA. Periprosthetic supracondylar femoral fractures following total knee arthroplasty: clinical comparison and related complications of the femur plate system and retrograde-inserted supracondylar nail. J Orthop Traumatol. 2014;15(3):201-7. https://doi.org/10.1007/s10195-014-0287-x Epub 2014 Apr 1.

8. Culp RW, Schmidt RG, Hanks G, Mak A, Esterhai JL, Heppenstall RB. Supracondylar fracture of the femur following prosthetic knee arthroplasty. Clin Orthop Relat Res. 1987;222:212-22.

9. Meluzio MC, Oliva MS, Minutillo F, Ziranu A, Saccomanno MF, Maccauro G: The use of knee mega-prosthesis for the management of distal femoral fractures: A systematic review. Injury. 2019, 13. pii: S0020-1383(19)30473-5. doi: https://doi.org/10.1016/j.injury.2019.08.011. [Epub ahead of print].

10. Beris AE, Lykissas MG, Sioros V, Mavrodontidis AN, Korompilias AV: Femoral periprosthetic fracture in osteoporotic bone after a total knee replacement: treatment with Ilizarov external fixation. J Arthroplasty. 2010, 25(7):1168.e912. doi: https://doi.org/10.1016/j.arth.2009.10.009. Epub 2010 Jan 22.

11. Sakai T, Ohzono K, Nakase T, Lee SB, Manaka T, Nishihara S. Treatment of periprosthetic femoral fracture after cementless total hip arthroplasty with Ilizarov external fixation. J Arthroplast. 2007;22(4):617-20 Epub 2006 Jun 21.

12. Simon RG, Brinker MR. Use of llizarov external fixation for a periprosthetic supracondylar femur fracture. J Arthroplast. 1999;14(1):118-21.

13. Hurson C, Synnott K, McCormack D. Above-knee llizarov external fixation for early periprosthetic supracondylar femoral fracture--a case report. Knee. 2005;12(2):145-7.

14. Khan MS, Di Giacomo LM, Meccariello L, Bisaccia M, Azzam W, Jatoi A, Rollo G: llizarov technique, satisfactory outcome with limited resources. Clin Cases Miner Bone Metab. 2018, 15(2):221-226. doi: https://doi.org/10.11138/ $\mathrm{ccmbm} / 2018.15 .2 .221$

15. Rorabeck $\mathrm{CH}$, Taylor JW. Classification of periprosthetic fractures complicating total knee arthroplasty. Orthop Clin North Am. 1999;30(2):209-14.

16. Felix NA, Stuart MJ, Hanssen AD. Periprosthetic fractures of the tibia associated with total knee arthroplasty. Clin Orthop Relat Res. 1997;345:113-24.

17. Falzarano G, Piscopo A, Grubor P, Rollo G, Medici A, Pipola V, Bisaccia M, Caraffa A, Barron EM, Nobile F, Cioffi R, Meccariello L. Use of common inflammatory markers in the long-term screening of total hip arthroprosthesis infections: our experience. Adv Orthop. 2017;2017:9679470. https://doi.org/10.1155/2017/9679470 Epub 2017 Aug 23

18. Nozaka K, Miyakoshi N, Saito H, Kijima H, Chida S, Tsuchie H, Shimada Y: Effectiveness of llizarov external fixation in elderly patients with pilon fractures. J Orthop Sci. 2020 Mar 26. pii: S0949-2658(20)30070-1. doi: https://doi.org/10.1016/j.jos.2020.02.018. [Epub ahead of print].

19. Herrera DA, Kregor PJ, Cole PA, Levy BA, Jönsson A, Zlowodzki M. Treatment of acute distal femur fractures above a total knee arthroplasty : systematic 
review of 415 cases (1981-2006). Acta Orthop. 2008;79(1):22-7. https://doi. org/10.1080/17453670710014716.

20. Fleischman AN, Chen AF. Periprosthetic fractures around the femoral stem: overcoming challenges and avoiding pitfalls. Ann Transl Med. 2015;3(16): 234. https://doi.org/10.3978/j.issn.2305-5839.2015.09.32.

21. Grubor P, Mitković M, Grubor M, Mitković M, Meccariello L, Falzarano G. Biomechanical stability of juvidur and bone models on osteosyntesic materials. Acta Inform Med. 2016;24(4):261-5.

22. Rollo G, Pichierri P, Grubor P, Marsilio A, Bisaccia M, Grubor M, Pace V Lanzetti RM, Giaracuni M, Filipponi M, Meccariello L: The challenge of nonunion and malunion in distal femur surgical revision. Med Glas (Zenica), 2019, 16(2). doi: https://doi.org/10.17392/1016-19. [Epub ahead of print].

23. Matlovich NF, Lanting BA, Vasarhelyi EM, Naudie DD, McCalden RW, Howard JL. Outcomes of surgical Management of Supracondylar Periprosthetic Femur Fractures. J Arthroplast. 2017;32(1):189-92. https://doi.org/10.1016/j. arth.2016.06.056 Epub 2016 Aug 3.

24. Brunner UH, Cordey J, Schweiberer L, Perren SM. Force required for bone segment transport in the treatment of large bone defects using medullary nail fixation. Clin Orthop Relat Res. 1994;301:147-55.

25. Falzarano G, Pica G, Medici A, Rollo G, Bisaccia M, Cioffi R, Pavone M, Meccariello L. Foot loading and gait analysis evaluation of nonarticular Tibial Pilon fracture: a comparison of three surgical techniques. J Foot Ankle Surg. 2018;57(5):894-8. https://doi.org/10.1053/j.jfas.2018.03.025 Epub 2018 Jun 15.

26. Robin G, Simon DO, Brinker M. Use of Ilizarov external fixation for a periprosthetic supracondylar femur fracture. J Arthroplast. 1999;14(1):118-21.

27. Nozaka K, Miyakoshi N, Sato T, Shimada Y. llizarov external fixation for a periprosthetic tibial fracture in severe osteoporosis: a case report. BMC Musculoskelet Disord. 2020;21 (1):145. https://doi.org/10.1186/s12891-020-3176-X.

28. Nozaka K, Miyakoshi N, Kashiwagura T, Kasukawa Y, Saito H, Kijima H, Chida S, Tsuchie H, Shimada Y. Effectiveness of distal tibial osteotomy with distraction arthroplasty in varus ankle osteoarthritis. BMC Musculoskelet Disord. 2020;21(1):31. https://doi.org/10.1186/s12891-020-3061-7.

29. Nozaka K, Miyakoshi N, Yuasa Y, Mita M, Shimada Y: Simultaneous Total Knee Arthroplasty and Ankle Arthrodesis for Charcot Neuroarthropathy. Case Rep Orthop. 2019, 7;2019:6136409. doi: https:/doi.org/10.1155/2019/ 6136409. eCollection 2019

30. Nozaka K, Shimada Y, Miyakoshi N, Yamada S, Kasukawa Y, Noguchi A. Pathological fracture of the femur in Alagille syndrome that was treated with low-intensity pulsed ultrasound stimulation and an llizarov ring fixator: a case report. BMC Musculoskelet Disord. 2014;15:225. https://doi.org/10. 1186/1471-2474-15-225.

31. Nozaka K, Shimada Y, Kimura Y, Yamada S, Kashiwagura T, Sakuraba T, Wakabayashi I. Successful treatment of nonunion with an llizarov ring fixator after ankle fracture for Charcot arthropathy: a case report. BMC Res Notes. 2014;7:503. https://doi.org/10.1186/1756-0500-7-503.

32. Teramoto A, Nozaka K, Kamiya T, Kashiwagura T, Shoji H, Watanabe K, Shimada Y, Yamashita T. Screw internal fixation and llizarov external fixation: a comparison of outcomes in ankle arthrodesis. J Foot Ankle Surg. 2020 59(2):343-6. https://doi.org/10.1053/j.jfas.2019.09.012.

\section{Publisher's Note}

Springer Nature remains neutral with regard to jurisdictional claims in published maps and institutional affiliations.

Ready to submit your research? Choose BMC and benefit from:
- fast, convenient online submission
- thorough peer review by experienced researchers in your field
- rapid publication on acceptance
- support for research data, including large and complex data types
- gold Open Access which fosters wider collaboration and increased citations
- maximum visibility for your research: over 100M website views per year
At BMC, research is always in progress.
Learn more biomedcentral.com/submissions

